\title{
A Comparison of the Effectiveness of Tincture of Iodine and Potassium Iodide on Chronic Sinusitis
} Patients with Biofilm

\author{
Rizwan M, Bozena W and Dale HR* \\ Department of Otolaryngology-Head and Neck Surgery, Keck School of Medicine of \\ the University of Southern California, USA
}

*Corresponding author: Dale HR, Caruso Department of Otolaryngology-Head and Neck Surgery, Keck School of Medicine of the University of Southern California, Los Angeles, USA, CA 90033, E-mail: dhrice@usc.edu

\section{Research Article \\ Volume 2 Issue 1}

Received Date: March 21, 2017

Published Date: March 30, 2017

DOI: $10.23880 /$ ooaj-16000149

\section{Abstract}

Objectives: Several factors may influence the results of bacteriological and fungal studies in chronic rhinosinusitus (CRS) patients. It is well established that antibiotics perform poorly against bacteria and fungi in biofilm. We investigated the potential utility of tincture of iodine and potassium iodide on bacterial and fungal elements within the biofilmin chronic rhinosinusitis patients.

Materials and Methods: Bacteriology was studied in 12 consecutive adult patients presenting with CRS who underwent functional endoscopic sinus surgery. Ethmoid tissue from all patients was treated with the same concentrations of tincture of iodine or potassium iodide at different time intervals. The ethmoid tissues were examined for Live/Dead bacterial and fungal cells by Baclight assay.

Results: Tincture of iodine and potassium iodide were able to kill bacterial and fungal cells in ethmoid tissue. We performed quantitative analysis and showed that tincture of iodine is slightly more effective than potassium iodide.

Conclusion: The tincture of iodine treatment on the ethmoid tissues yielded a higher percentage of dead bacterial or fungal cells compared to potassium iodide treatment with similar concentrations.

\section{Introduction}

Sinusitis affects 37 million people each year, making it one of the most common health problems in the US [1-3]. It is a common disease and has great impact on the quality of daily life. Chronic rhinosinusitis (CRS) is a common health problem, with significant medical costs and impact on general health [4]. Chronic rhinosinusitis is an inflammatory disease in which virus, bacteria, and fungi play a distinct role [5]. Antibiotic therapy has been advocated for the treatment of acute bacterial rhinosinusitis but its role in chronic rhinosinusitis remains unclear [6]. The pathophysiology of CRS includes inflammation or disruption of the mucous membranes from allergies, particles, and infections, most commonly bacterial and fungal infections. Earlier data has stated that 93\% of all cases of CRS were mold or fungal related [7], but this now seems less certain. There is conflicting data on the effectiveness of existing treatments. Treatment of CRS is mainly symptomatic, and underlying inflammation 


\section{Otolaryngology Open Access Journal}

is the key element that is treated [8]. Even if surgery showed a higher quality of life improvement than medical treatment, the latter is generally proposed as initial treatment $[9,10]$. Corticosteroids are the most effective drug for treating CRS with or without polyposis, even if the modality of administration (oral, intranasal spray, and nasal nebulization) remains controversial $[11,12]$. Many patients with CRS have biofilm and it is well established that antimicrobials work poorly when biofilm is present. The aim of this study was to compare the effectiveness of tincture of iodine and potassium iodide on live bacterial/ fungal cells in biofilm from the ethmoid tissues of CRS patients who underwent endoscopic sinus surgery. Both have been used for over a century as anti-infectives.

\section{Materials and Methods}

\section{Reagents}

Tincture of iodine was obtained from a local pharmacy. The active ingredients contain $2 \%$ iodine, $2.4 \%$ of sodium iodide constituted in $47 \%$ of antiseptic alcohol. Potassium iodide, oral solution was manufactured by UPSHER-Smith laboratories, Inc. Minneapolis, MN and obtained from a pharmacy.

\section{Patients' Selection}

This study was approved by the University of Southern California IRB for the Health Sciences Campus. All selected patients in this study had chronic rhinosinusitis. All had persistent inflammation in one or more sinuses and had failed maximum medical therapy demonstrated by examination and by CT scan, but they had not undergone any operative procedures prior to this study. All patients had endoscopic sinus surgery performed to open the drainage pathways of the affected sinuses.

\section{Tissue Collection}

All CRS patients had random pieces of sinus mucosal tissue harvested from the ethmoid sinuses during their procedure. Tissue was immediately transported to our laboratory. Tissue was then stored in Dulbecco's Modified Eagle's Medium (Invitrogen Corp., Carlsbad, CA) and washed thoroughly with cold PBS twice in separate wells. Tissue for H\&E staining was fixed with $10 \%$ formaldehyde overnight at room temperature. Tissue for Baclight was used fresh. All tissue was cut into two pieces and one half was used in OCT block and the other half was used to make a paraffin block.
The OCT blocks were used for Baclight assay and paraffin sections were used for $\mathrm{H} \& \mathrm{E}$ staining. All the patient samples were de-identified by the person collecting the specimens and labeled from 1 through 12 to ensure blinding of the researchers analyzing the specimens. Five $\mathrm{mm}$ sections were cut from both the blocks.

\section{Biofilm Identification}

Our group has previously validated this protocol to identify the location of biofilm in the tissue by using $\mathrm{H} \& \mathrm{E}$ staining [13]. We have also developed specific probes to identify different bacterial species and fungi using FISH [14].

\section{Baclight Assay}

Baclight analysis was performed using fresh tissue. The specimens were processed fresh and analyzed immediately. The sections were treated with equimolar solution of tincture of iodine or potassium iodide for fixed time intervals. The control arm was treated with $30 \%$ ethyl alcohol only. Following washing, the section on the slide was then immersed in $1 \mathrm{ml}$ of sterile water containing $1.5 \mu \mathrm{l}$ aliquots of component A (syto9) and component B (propidium iodide) of the LIVE/DEAD Baclight kit (Invitrogen, Molecular Probes, Eugene, Oregon) were added. After incubation for 15 minutes at room temperature in darkness, each section was rinsed in sterile water to remove excess stain. The specimens were mounted on cover slips for analysis by confocal microscopy. With this combination of stains, live bacteria cell membranes were stained fluorescent green, whereas those with damaged membranes showed fluorescent red.

FISH protocol: Our FISH protocol as described previously uses species-specific probes to identify bacteria and fungi within the biofilm [14].

\section{Statistical Analysis}

Quantitative analysis in this study was performed using Pro Image. Digital scans of the entire Baclight assay sections were analyzed using Image Scope imaging software (Aperio, Vista, CA). This software classifies dead and live bacterial cells, which appear as the colors red, and green, respectively. The results of this study were analyzed using the SPSS software (Version 16.0; SPSS, Inc., New York, NY) as we have done before [14]. In all analyses, values of $\mathrm{p}<0.05$ were considered statistically significant. 


\section{Otolaryngology Open Access Journal}

\section{Results}

Twelve CRS patients undergoing ESS were recruited for this study. The study group consisted of 6 females and 6 males with a mean age of 55 years. All patients had the disease for more than a year. Two independent methods ( $\mathrm{H}$ \& $\mathrm{E}$ staining and FISH) were used to detect the presence of biofilm. We found all patients were positive for biofilm but the degree of biofilm presence varied among patients [14]. Looking at the species data from the FISH protocol, 8/12 (67\%) patients had Staphylococci aureus, 4/12 (34\%) patients had H. influenza, 3/12 (25\%) patients had Pseudomonas aeruginosa and 2/12 patients had yeast (Table 1). Using the Baclight assay, patients' specimens showed bacterial biofilm in red fluorescent at the same location as in the FISH. This was done by serially sectioning the tissue with the fresh tissue going for Baclight and the very next section going for FISH. An unpaired T-test was performed to compare the effectiveness between the tincture of iodine and the potassium iodide groups at 10 minutes and 30 minutes. The specimens treated with tincture of iodine or potassium iodide for a short time (10 minutes) showed similar dead cells $(\mathrm{p}=0.4528)$ (Figure 1). When the specimens were treated for a longer time (30 minutes), tincture of iodine proved to be more effective and showed more killing of the bacterial cells than potassium iodide in all patients (Figure 2A, 2B \& 2C). A quantitative analysis using Pro image showed significant differences in the killing of bacterial cells in sinus tissue treated with tincture of iodine compared to potassium iodide at the 30 minute time interval ( $p>$.0001) (Figure 3).

\begin{tabular}{|c|c|c|}
\hline Total cases (n) & $\mathbf{1 2}$ & \\
\hline Sex & & \\
\hline M & 6 & \\
\hline F & 6 & \\
\hline Age (range) & & \\
\hline M & $28-68$ years & \\
\hline F & $31-70$ years & \\
\hline Organisms & & \\
\hline S. aureus & 8 & $67 \%$ \\
\hline H. influenza & 4 & $34 \%$ \\
\hline P. aeruginosa & 3 & $25 \%$ \\
\hline Yeast & 2 & $17 \%$ \\
\hline
\end{tabular}

Table 1: Clinical Characteristic, demographics, and biofilm presence in chronic rhinosinusitis patients.

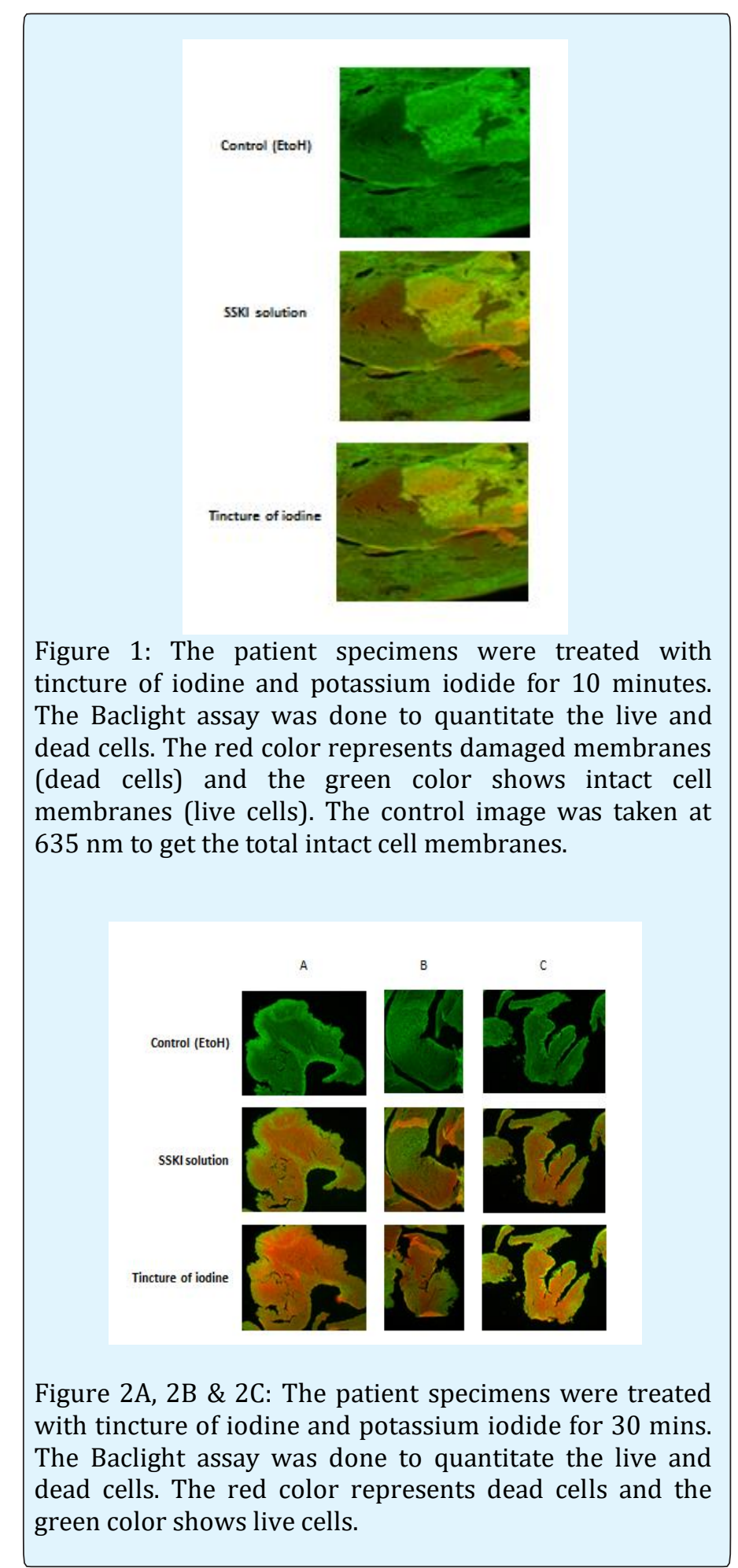




\section{Otolaryngology Open Access Journal}

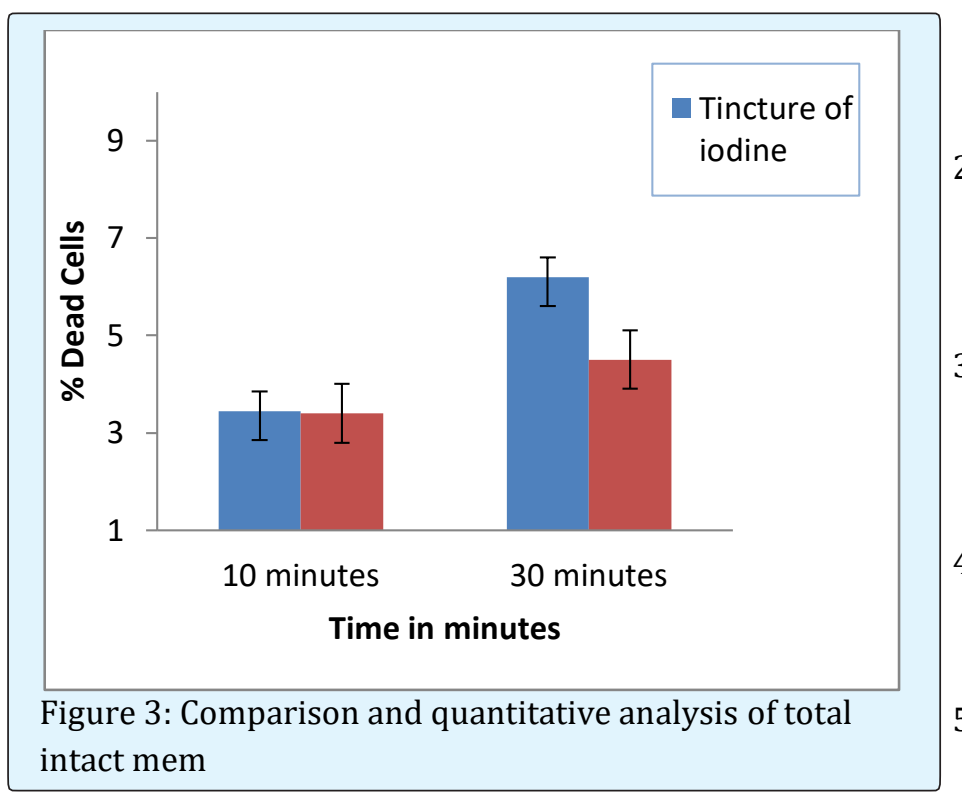

\section{Discussion}

The real importance of biofilm in CRS is not established. Part of this problem is the difficulty in identifying biofilm in tissue. Until recently, identification required expensive and time-consuming equipment and techniques, such as confocal microscopy or FISH. Recently our group showed how biofilm could be identified using simple H\&E preparations [13]. It seems that biofilm is more commonly present the harder one looks for it. Still its role is unclear. This is the first study to show in vitro that both tincture of iodine and potassium iodide kill bacterial cells within biofilm. However tincture of iodine with longer exposure time showed superior killing of bacterial cells compared to potassium iodide. Our data clearly indicates that tincture of iodine is more effective in chronic rhinosinusitis than potassium iodide. Tincture of iodine could potentially be more useful in clinic as opposed to potassium iodide for the treatment of this type of patient. It is possible that applying tincture of iodine to the sinus tissues at the completion of the procedure would improve the long term outcome in those patients with biofilm. Similarly, tincture of iodine could be added to the saline irrigation solution in the postoperative period. Further work needs to be done to fully assess its efficacy.

\section{References}

1. Benninger M, Ferguson BJ, Hadley JA, Hamilos DL, Jacobs M, et al. (2003) Adult chronic rhinosinusitis: Definitions, diagnosis, epidemiology and pathophysiology. Otolaryngol Head Neck Surg 129(3): 1-32.

2. Lusk R, Bothwell MR, Piccirillo J (2006) Long-term follow-up for children treated with surgical intervention for chronic rhinosinusitis. Laryngoscope 116(12): 2099-2107.

3. Rubin MA, Gonzales R, Sande MA (2005) Infections of the upper respiratory tract. In: Kasper DL, et al. [Eds]. Harrison's Principles of Internal Medicine 16 ${ }^{\text {th }}$ (Edn.) New York, NY: McGraw-Hill pp: 185-201.

4. Bhattacharyya N (2009) Contemporary assessment of the disease burden of sinusitis. Am J Rhinol Allergy 23(4): 392-395.

5. Hamilos DL (2015) Drivers of chronic rhinosinusitis: inflammation versus infection. J Allergy Clin Immunol 136(6): 1454-1459.

6. Klossek JM, Chidiac C (2001) Current approaches to community acquired acute maxillary rhinosinusitis or sinusitis in France and literature review. Rhinology suppl 17: 1-38.

7. Ponikau JU, Sherris DA, Kern EB, Homburger HA, Frigas E, et al. (1999) The diagnosis and incidence of allergic fungal sinusitis. Mayo Clin Proc 74(9): 877884.

8. Thomas M, Yawn BP, Price D, Lund V, Mullol J, et al. (2008) EPOS primary care guidelines: European position paper on the primary care diagnosis and management of rhinosinusitis and nasal polyps 2007a summary. Prim Care Respir J 17(2): 79-89.

9. Smith TL, Kern R, Palmer JN, Schlosser R, Chandra RK, et al. (2013) Medical therapy vs surgery for chronic rhinosinusitis: a prospective, multi-institutional study with 1-year follow-up. Int Forum Allergy Rhinol 3(1): 4-9.

10. Young LC, Stow NW, Zhou L, Douglas RG (2012) Efficacy of medical therapy in treatment of chronic rhinosinusitis. Allergy Rhinol (Providence) 3(1): 8-12.

11. Alobid I, Mullol J (2012) Role of medical therapy in the management of nasal polyps. Curr Allergy Asthma Rep 12(2): 144-153.

12. Ah-See KL, Mac Kenzie J, Ah-See KW (2012) Management of chronic rhinosinusitis. BMJ 345: 7054 . 


\section{Otolaryngology Open Access Journal}

13. Hochstim CJ, Choi JY, Lowe D, Masood R, Rice DH (2010) Biofilm detection with hematoxylin-eosin staining. Arch Otolaryngol Head \& Neck Surg 136(5): 453-456.
14. Arjomandi H, Gilde J, Zhu S, Delaney S, Hochstim C, et al. (2013) Relationship of eosinophils and plasma cells to biofilm in chronic rhinosinusitis. Am J Rhinol Allergy 27(4): 85-90. 